\title{
Aislamiento de enterobacterias de tenebrio molitor (coleoptera: tenebrionidae) como organismos degradadores del poliestireno expandido bajo condiciones de laboratorio
}

\author{
Verónika Isela Vera Marmanillo \\ vveram@uandina.edu.pe \\ Círculo de Investigaciones Ambientales por la Sostenibilidad CIAS \\ Universidad Andina del Cusco UAC \\ Bryan Choque Farfán \\ 018100452b@uandina.edu.pe \\ Círculo de Investigaciones Ambientales por la Sostenibilidad CIAS \\ Universidad Andina del Cusco UAC \\ Katerinne Lisset Soto Camino \\ 016201098a@uandina.edu.pe \\ Círculo de Investigaciones Ambientales por la Sostenibilidad CIAS \\ Universidad Andina del Cusco UAC \\ Giovanni Jesús Solórzano Llasa \\ 018101470d@uandina.edu.pe \\ Círculo de Investigaciones Ambientales por la Sostenibilidad CIAS \\ Universidad Andina del Cusco UAC \\ Betsy Alejandra Huayllani Nina \\ 018100851d@uandina.edu.pe \\ Círculo de Investigaciones Ambientales por la Sostenibilidad CIAS \\ Universidad Andina del Cusco UAC \\ Afiliación institucional: Universidad Andina del Cusco- UAC
}

\section{RESUMEN}

El proyecto de investigación se realizó con la premisa de hacer uso de la biotecnología como una alternativa de solución para un problema aún difícil de resolver como es la biodegradación de plásticos de un solo uso. El objetivo fue aislar bacterias de la microbiota intestina de las larvas de Tenebrio molitor como organismos degradadores del poliestireno expandido, identificar el género de bacterias aisladas, determinar el volumen de poliestireno consumido por las larvas como fuente única de alimentación, bajo condiciones de laboratorio y finalmente valorar la composición bioquímica de los desechos generados como parte del proceso de digestión de las larvas de Tenebrio 
molitor. El tracto digestivo extraído fue introducido en un microtubo eppendorf con 0,2 $\mathrm{mL}$ de agua peptonada al $10 \%$ y usando el vórtex por 30s se logró separar los microorganismos de las paredes del tejido, se hizo un cultivo en Chromagar y el repique en agar telurito de $\mathrm{K}$ a $37^{\circ} \mathrm{C}$ por 48 horas, para la identificación de la especie de las enterobacterias aisladas. De acuerdo con la coloración de las colonias aisladas, y por el patrón de identificación, se pudo determinar que se trataba de la especie Enterococcus faecalis ATCC $29212\left(\mathrm{Gram}^{+}\right)$. La composición bioquímica de los desechos generados como parte del proceso de digestión de las larvas, por espectrometría, evidenció que los polímeros sintéticos habían sido digeridos por las enterobacterias generó excretas contenidas en $\mathrm{O}, \mathrm{N}, \mathrm{P}$ y $\mathrm{K}$ demostrando la capacidad de convertir sustancias no biodegradables, en sustancias químicas potencialmente asimilables.

Palabras clave: microbiota intestinal; tenebrio molitor; composición bioquímica; poliestireno expandido 


\title{
Isolation of tenebrio molitor enterobacteriaceae (coleoptera:
} tenebrionidae) as degrading organisms of expanded polystyrene under laboratory conditions

\begin{abstract}
The research project was carried out with the premise of making use of biotechnology as an alternative solution for a problem that is still difficult to solve, such as the biodegradation of single-use plastics. The objective was to isolate bacteria from the intestinal microbiota of the larvae of Tenebrio molitor as degrading organisms of expanded polystyrene, identify the genus of isolated bacteria, determine the volume of polystyrene consumed by the larvae as the sole source of food, under conditions of laboratory and finally assess the biochemical composition of the waste generated as part of the digestion process of the larvae of Tenebrio molitor. The extracted digestive tract was introduced into an eppendorf microtube with $0.2 \mathrm{~mL}$ of $10 \%$ peptone water and using the vortex for 30s it was possible to separate the microorganisms from the tissue walls, a culture was made on Chromagar and the peal on tellurite agar of $\mathrm{K}$ at $37^{\circ} \mathrm{C}$ for 48 hours, for the identification of the species of the isolated Enterobacteriaceae. According to the coloration of the isolated colonies, and by the identification pattern, it could be determined that it was the species Enterococcus faecalis ATCC 29212 (Gram +). The biochemical composition of the waste generated as part of the digestion process of the larvae, by spectrometry, showed that the synthetic polymers had been digested by the Enterobacteriaceae generated excreta contained in $\mathrm{O}, \mathrm{N}, \mathrm{P}$ and $\mathrm{K}$ demonstrating the ability to convert non-biodegradable substances, in potentially assimilable chemicals.
\end{abstract}

Keywords: gut microbiota; tenebrio molitor; biochemical composition; expanded polystyrene

Artículo recibido: 05 octubre. 2021 Aceptado para publicación: 02 noviembre 2021 Correspondencia: vveram@uandina.edu.pe Conflictos de Interés: Ninguna que declarar 


\section{INTRODUCCIÓN}

La contaminación producida por los polímeros no biodegradables ha experimentado un crecimiento exponencial en los últimos años, razón por lo que se han dedicado esfuerzos a la investigación en la degradación de éstos. La búsqueda de diversas soluciones, como el uso de plásticos biodegradables, compuestos de almidón o colágeno que permanecen poco tiempo en el ambiente, es una alternativa ecoamigable para mitigar los efectos de los residuos generados por actividad antrópica. Sin embargo, una desventaja, es el elevado costo de producción en comparación al costo de los plásticos de un sólo uso. Uno de los polímeros derivados del petróleo más utilizados en el mundo, es el poliestireno expandido, al igual que el polietileno de alta y baja densidad, el polipropileno y el PVC con una demanda mundial de aproximadamente 22 millones de toneladas al año. (Góngora, 2018).

Los riesgos ambientales recurrentes ocasionados por la producción de espuma de poliestireno es la liberación de sustancias químicas sumamente tóxicas para la atmósfera, incrementando el potencial de los gases de efecto invernadero. Pero sin duda, la contaminación visual, social y ambiental que genera el residuo del PS, al ser considerado el plástico más persistente, es consecuencia de su ciclo de vida tan efímero.

El estireno, es un hidrocarburo cuya fórmula $\mathrm{C} 8 \mathrm{H} 8$ que al ser polimerizado da como resultado el poliestireno (PS), que es un termoplástico [- $\left.\mathrm{CH}\left(\mathrm{C}_{6} \mathrm{H}_{5}\right) \mathrm{CH} 2-\right] \mathrm{n}$, muy frágil a temperatura ambiente, por lo cual se modifica mediante la adición de polibutadieno, para mejorar su resistencia al impacto llamándose así poliestireno de alto impacto (HIPS, por sus siglas en inglés) también conocido como poliestireno de espuma. Es en ese contexto, que los termoplásticos tienen características hidrófobas que los hace resistentes a la hidrólisis, incluso el uso de retardantes y antioxidantes sintéticos en su elaboración, los convierten en materiales muy resistentes. (Ho, 2017).

La bacteria Ideonella sakaiensis, ha sido descrita como la responsable de la degradación o desintegración del tereftalato de polietileno PET a condiciones de laboratorio de $30^{\circ} \mathrm{C}$ constantes durante incubación de 6 semanas. (Yoshida \& Kosuda, 2016).

Estudios realizados por Yang \& Yang, (2015) han mostrado la capacidad para degradar poliestireno por la bacteria Exiguobacterium sp. que probablemente haya sido encontrada en el tubo digestivo de Artemia franciscana, un mesocrustáceo utilizado como alimento de peces por su alto nivel proteico. El género Exiguobacterium, son bacterias descritas 
como gram positivas, anaerobias, que han logrado ser aisladas en diversos ecosistemas entre una temperatura de 12 a $55^{\circ} \mathrm{C}$. Este género de bacterias se ha usado para aplicaciones biotecnológicas.

La revista de ciencias Environmental Science and Technology (2015), indicó que la bacteria Exiguobacterium sp. podría tener la capacidad de degradar el poliestireno.

El trabajo de investigación de Velasco (2017), titulado Biodegradación del polietileno de baja densidad, mediante el uso del lepidóptero Galleria mellonella bajo condiciones térmicas controladas realizado en Perú, determinó ciertas condiciones y variables bajo un diseño experimental, las que refiere pertinentes para lograr que el gusano de seda biodegrade polietileno de baja densidad, esta investigación se realiza bajo una metodología cuantitativa de tipo aplicada. Cabe resaltar, que en este texto se especifican características propias del organismo, tales como: tamaño, alimentación, color y muda. El proyecto de investigación tuvo como objetivos aislar bacterias de la microbiota intestinal en las larvas de Tenebrio molitor como organismos degradadores del poliestireno expandido, bajo condiciones de laboratorio, identificar el género de bacterias aisladas de la microbiota intestinal, determinar el volumen de poliestireno consumido por las larvas y finalmente valorar la composición bioquímica de los desechos generados como parte del proceso de digestión de las larvas de Tenebrio molitor.

Este trabajo tiene relevancia científica y teórica, porque proporcionará información sobre la aplicación de la biotecnología como herramienta en pro de la mitigación del impacto por residuos de Tecnopor por lo que este proyecto de investigación se convierte en antecedente, en un instrumento de consulta y de guía para estudios semejantes que puedan elaborarse, tanto a nivel nacional como internacional.

\section{MATERIALES Y MÉTODOS}

La investigación tiene un enfoque cuantitativo y diseño experimental, no paramétrico. A fin de determinar las condiciones óptimas de humedad relativa (HR), temperatura $\left(\mathrm{T}^{\mathbf{o}}\right) \mathrm{y}$ horas lux (hl) (Pinto, 2007), para desarrollo de larvas de Tenebrio molitor, se sometió a 4 tratamientos diferenciados en condiciones establecidas. A fin de determinar el consumo y degradación del poliestireno expandido bajo dieta única se hizo la siguiente diferenciación gravimétrica en relación con el balance de la biomasa y el balance del poliestireno consumido con relación a las excretas producidas a condiciones de $\mathrm{HR} \mathrm{y}^{\circ} \mathrm{T}$ específicas. 
Tabla N¹: Balance másico entre el peso inicial de los tenebrios y la variación de biomasa con relación al balance de la diferencia másica del poliestireno consumido por los tenebrios

\begin{tabular}{|c|c|c|c|c|c|c|c|c|c|c|}
\hline \multirow[b]{2}{*}{ 类 } & \multirow{2}{*}{ 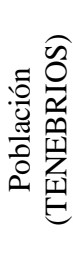 } & \multicolumn{3}{|c|}{ Balance peso vivo (g) } & \multicolumn{4}{|c|}{ Balance de excretas (g) } & \multirow[b]{2}{*}{$\begin{array}{c}\text { Humed } \\
\text { ad } \\
\text { relativa } \\
\%\end{array}$} & \multirow[b]{2}{*}{$\begin{array}{c}\text { Tempe } \\
\text { ratura } \\
\left({ }^{\circ} \mathrm{C}\right)\end{array}$} \\
\hline & & $\begin{array}{l}\text { Peso } \\
\text { inicial de } \\
\text { tenebrios } \\
\quad(\mathrm{g})\end{array}$ & $\begin{array}{l}\text { Peso final } \\
\text { de } \\
\text { tenebrios } \\
(\mathrm{g})\end{array}$ & $\begin{array}{l}\text { Variación } \\
\text { de Biomasa } \\
\text { (g) }\end{array}$ & $\begin{array}{c}\text { Peso } \\
\text { inicial } \\
\text { del } \\
\text { poliestire } \\
\text { no }(\mathrm{g})\end{array}$ & $\begin{array}{l}\text { Peso } \\
\text { final del } \\
\text { poliestir } \\
\text { eno }(\mathrm{g})\end{array}$ & $\begin{array}{l}\text { Poliestir } \\
\text { eno } \\
\text { digerido } \\
\text { (g) }\end{array}$ & $\begin{array}{l}\text { Peso } \\
\text { de } \\
\text { excreta } \\
(\mathrm{g})\end{array}$ & & \\
\hline
\end{tabular}

\section{Elaboración propia}

\subsection{Extracción del tracto digestivo de las larvas}

El sacrificio de las larvas se realizó por enfriamiento, manteniéndolos durante 15 minutos a $-2^{\circ} \mathrm{C}$ en la congeladora, antes de ser utilizados. Los especímenes sacrificados serán sometidos a desinfección en etanol $95 \%$ por 2 min.

Posteriormente fueron sumergidos en solución salina al $0.7 \%$, fueron instalados en el estereoscopio para disección y extracción de tubo digestivo, usando tijeras para microcirugía, y agujas entomológicas para realizar los cortes ventrales en la zona anal y en la zona cefálica. Luego, se realizó un corte longitudinal con las tijeras. El tracto digestivo fue extraído cortando las dos extremidades de este con el fin de separarlo del individuo (Vasanthakumar et al., 2006; Vasanthakumar et al., 2008). El tracto digestivo fue introducido en un microtubo eppendorf con $0,2 \mathrm{~mL}$ de agua peptonada al $10 \% \mathrm{y}$ usando el vórtex por 30s se logró separar los microorganismos de las paredes del tejido (Schloss et al., 2006; Vasanthakumar et al., 2006).

\section{Figura1: Extracción del tracto digestivo}

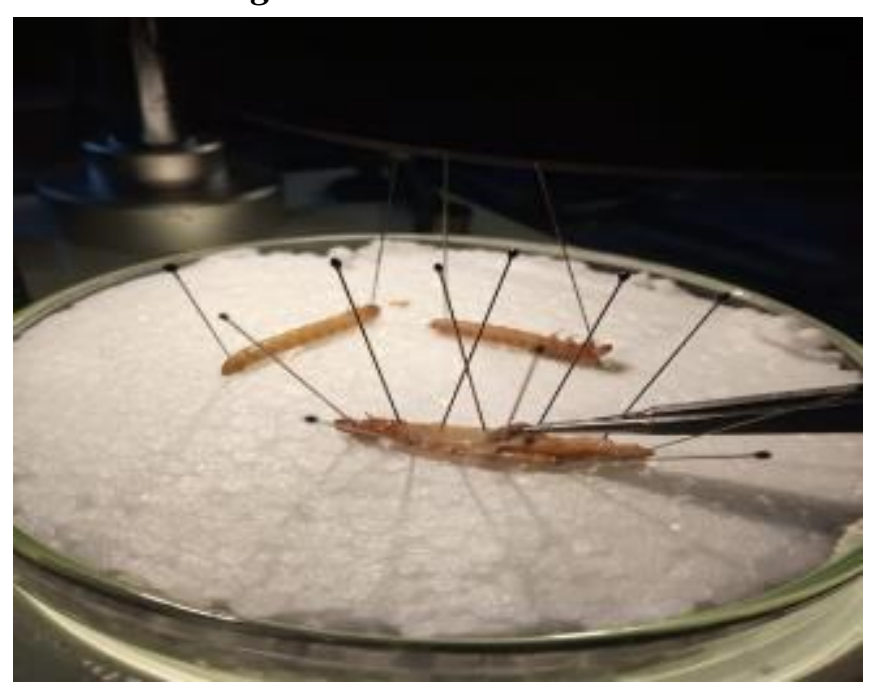

Fuente: Propia 
Se tuvo una población de 1393 individuos, divididos en 4 muestras al inicio del proyecto, estas 4 muestras diferenciadas de individuos de tenebriónidos, estuvieron a cargo de los investigadores quienes eran responsables de la crianza y aplicación experimental de la biodegradación, las muestras estuvieron distribuidas de la siguiente manera:

Tabla N'2: Población y muestra

\begin{tabular}{|c|c|}
\hline Muestra & $\mathbf{N}^{\mathbf{o}}$ de individuos \\
\hline 1 & 439 \\
\hline 2 & 420 \\
\hline 3 & 256 \\
\hline 4 & 278 \\
\hline Total & $\mathbf{1 3 9 3}$ \\
\hline
\end{tabular}

Elaboración propia

\subsection{Técnicas de análisis de datos}

- El análisis bioquímico de las excretas con la técnica de MEB y EDS.

- El análisis microbiológico en medios de cultivo específico para la determinación de especie de enterococos en agar telurito de potasio por observación microscópica.

- Técnica gravimétrica para el balance de la biomasa y el consumo de poliestireno expandido en relación con las excretas producidas.

\subsubsection{Instrumentos y técnicas de recolección de datos}

\section{Para la crianza de Tenebrio molitor}

\section{Instrumento}

Los instrumentos de recolección de datos fueron elaborados por los investigadores con el fin de tener una bitácora de registro cada 3 días, durante 39 días, donde se realizó un seguimiento sistemático considerando datos como: las horas de registro, la temperatura ambiental $\mathrm{T}^{\mathrm{o}}$, la Humedad relativa $\mathrm{HR}$, el número de individuos, empupamiento, peso inicial Wi y peso final Wf del poliestireno expandido, sometido a biodegradación a fin de hacer un balance de la diferencia másica inicial y final.

\section{Técnica}

La técnica empleada fue la observación y corroboración de información en base a gravimetría, para verificar el balance másico diferencial del poliestireno sometido a degradación. 


\section{Para el análisis del contenido de las excretas}

\section{Técnicas}

- Técnica de microscopía de barrido electrónico MEB

- Técnica de espectroscopía EDS

\section{Instrumentos}

- Microscopio de barrido electrónico (imágenes) equipo de marca Hitachi modelo SU8230.

- Espectrómetro (espectroscopía de 3 espectros) de energía dispersiva marca BRUKER modelo XFlash 6160.

\section{Para la determinación de las enterobacterias}

\section{Técnica}

- Microscopía óptica

- Tinción GRAM

- Repique bacteriano en agar específico

\section{Instrumento}

- Microscopio electrónico

- Chromagar

- Agar Telurito de potasio

\section{RESULTADOS}

Las bacterias de la microbiota intestinal de las larvas de Tenebrio molitor como organismos degradadores del poliestireno expandido, bajo condiciones de laboratorio, fueron aisladas. Los medios chromagar y agar sangre fueron los idóneos para la proliferación, a una temperatura de incubación de $37^{\circ} \mathrm{C}$ por 48 horas, formando colonias cremosas, similares morfológicamente y con coloración reactiva en el caso específico del chromagar para enterobacterias, determinando por tinción Gram, que se trataba de enterococos Gram positivos.

Para la determinación del género de las enterobacterias se utilizó un medio específico para la proliferación de enterococos. El medio de cultivo diferencial para bacterias reductoras del telurito de potasio $\mathrm{K}$, especialmente indicado para distinguir entre miembros del grupo enterococo degradadores de la esculina. Se logró identificar no sólo el género sino también la especie, identificando a la especie Enterococcus faecalis ATCC 29212. 
Figura 2: Enterococcus faecalis con tinción Gram

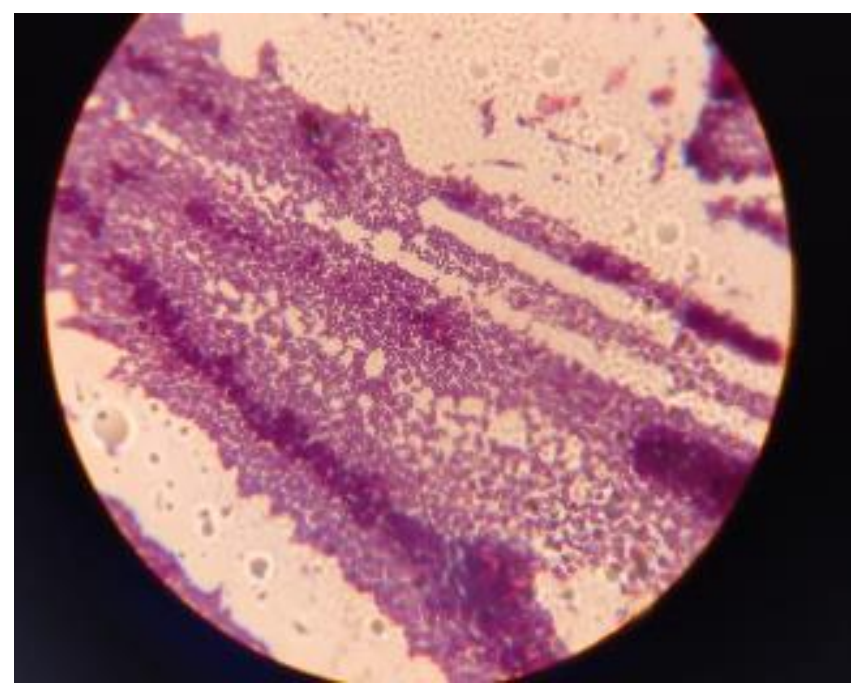

Se determinó el volumen de poliestireno consumido por las larvas de Tenebrio molitor como fuente única de alimentación, bajo condiciones de laboratorio. Durante 39 días de monitoreo sistemático por parte de los investigadores, se evaluó el balance de las excretas de los tenebriónidos expresado en gramos, y que, por diferencia másica, se pueda establecer la cantidad de poliestireno digerido, determinando por gravimetría una masa fecal de $0.3 \mathrm{~g}$ en la muestra M04 y 0.13g en la muestra M02 en el día 8 respectivamente, y $0,14 \mathrm{~g}$ en la muestra M02 el día 11, siendo los días de mayor gramaje. Al mismo tiempo se estableció por diferencia gravimétrica, los pesos inicial y final del poliestireno por cada uno de los tratamientos, evidenciando que sí había consumo del polímero de estireno.

Al realizar los estudios bioquímicos a los desechos generados por las larvas de Tenebrio Molitor, no se encontró trazas de poliestireno expandido, (Daviran, 2017) indica en sus resultados obtenidos que se ha logrado adquirir una materia fecal de 0.0307 gr en un periodo de 4 días del consumo de Poliestireno de densidad $10(\mathrm{~kg} / \mathrm{m} 3)$, mientras que en el poliestireno evaluado de densidad $40(\mathrm{~kg} / \mathrm{m} 3)$ se obtuvo una masa fecal de $0.1635 \mathrm{~g}$ en un periodo de 8 días.

La evaluación de cada espectro, en la muestra M01 denotó que los elementos descritos como el oxígeno $\mathrm{O}$ está presente en un porcentaje atómico del $50.45 \%$ +- un error relativo de $12.58 \%$, el fósforo $\mathrm{P}$ en un $2.14 \%$ del porcentaje atómico, el potasio $\mathrm{K}$ en un $8.87 \%$, el nitrógeno $\mathrm{N}$ en $35.66 \%$, el cloro $\mathrm{Cl}$ en $0.78 \%$ el azufre $\mathrm{S}$ en $0.51 \%$ y el Ca en $0.39 \%$. Se ha evidenciado un incremento sustancial del oxígeno, del nitrógeno, potasio y fósforo (en menor proporción), elementos importantes para considerar una materia fecal con 
potencial de nutrientes, esto traduce el hecho de que las excretas de los tenebriónidos, convirtieron los polímeros en sustancias químicas que podrían aportar nutrientes al suelo y lograron eliminar los relictos de poliestireno expandido.

Figura 3: Espectrometría de los elementos químicos de las excretas de Tenebrio molitor, espectro-M01, en base a los picos de energía

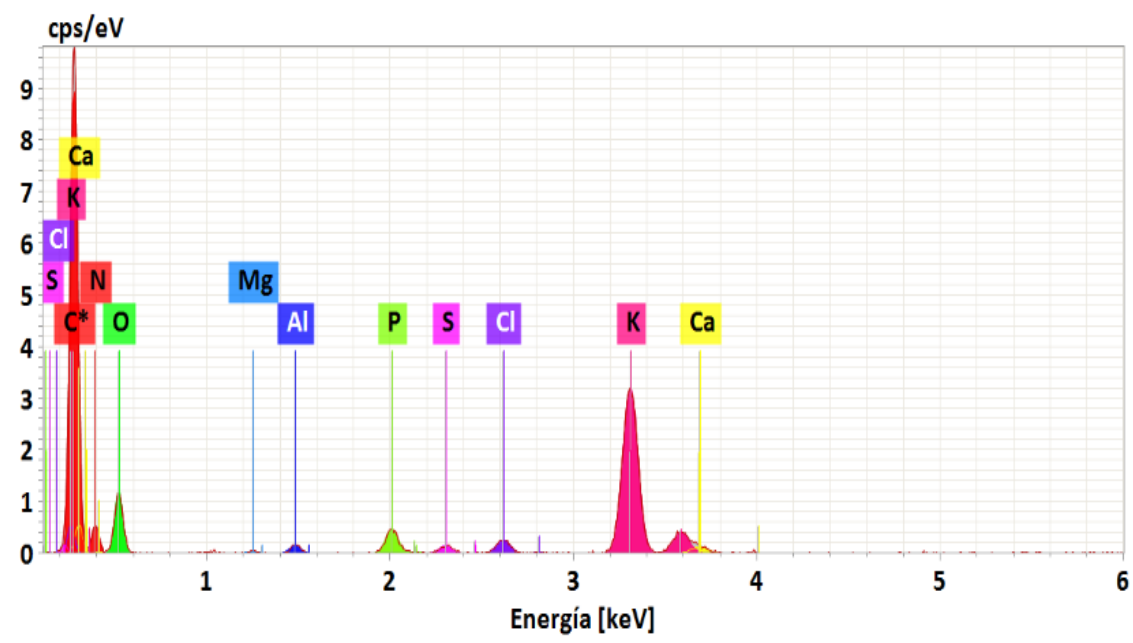

Figura 4: Imagen por Microscopía electrónica de barrido SEM - M01

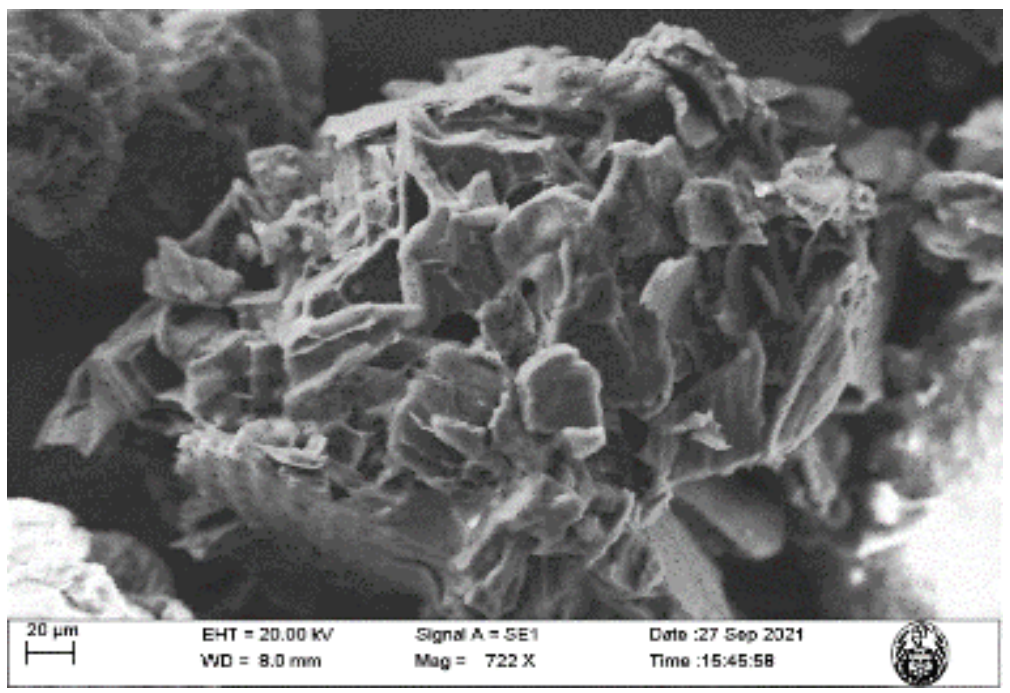

Fuente: SEM - UNI

La imagen a escala $20 \mathrm{Um}$, con energía dispersiva de $20.00 \mathrm{KV}$, magnitud $722 \mathrm{X}$ muestra que no hay evidencia de polímeros fragmentados. 
Figura 5: Imagen por Microscopía electrónica de barrido SEM - M01

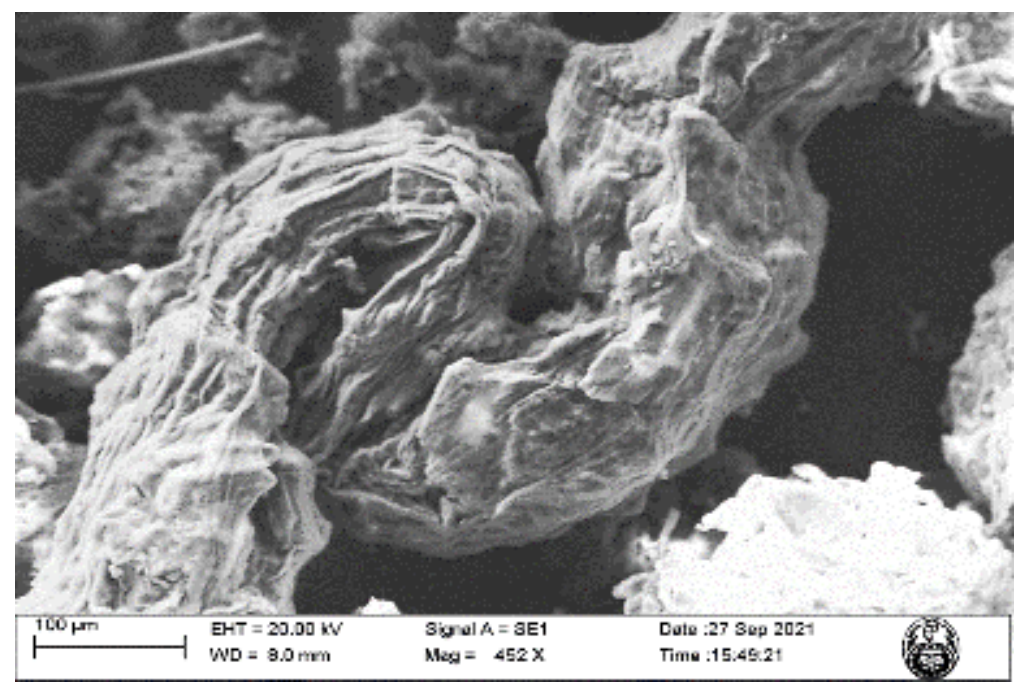

Fuente: SEM - UNI

La imagen a escala $100 \mathrm{Um}$, con energía dispersiva de $20.00 \mathrm{KV}$, magnitud $452 \mathrm{X}$ muestra que no hay evidencia de polímeros fragmentados. Habiendo evaluado cada espectro, en la muestra M02 se observó que los elementos descritos como el oxígeno O está presente en un porcentaje atómico del $56.78 \%$ +- un error relativo de $11.84 \%$, el fósforo $\mathrm{P}$ en un $14.56 \%$ del porcentaje atómico, el potasio $\mathrm{K}$ en un $12.80 \%$, el nitrógeno $\mathrm{N}$ en $11.80 \%$, el cloro $\mathrm{Cl}$ en $1.11 \%$ el azufre $\mathrm{S}$ en $2.69 \%$ y el $\mathrm{Ca}$ en $1.13 \%$. Se ha evidenciado un incremento sustancial del oxígeno, del nitrógeno, potasio y fósforo, elementos importantes para considerar una materia fecal con potencial de nutrientes, esto traduce el hecho de que las excretas de los tenebriónidos, convirtieron los polímeros en sustancias químicas que podrían aportar nutrientes al suelo y lograron eliminar los relictos de poliestireno expandido.

Figura 6: Espectrometría de los elementos químicos de las excretas de Tenebrio molitor, espectro-M02, en base a los picos de energía

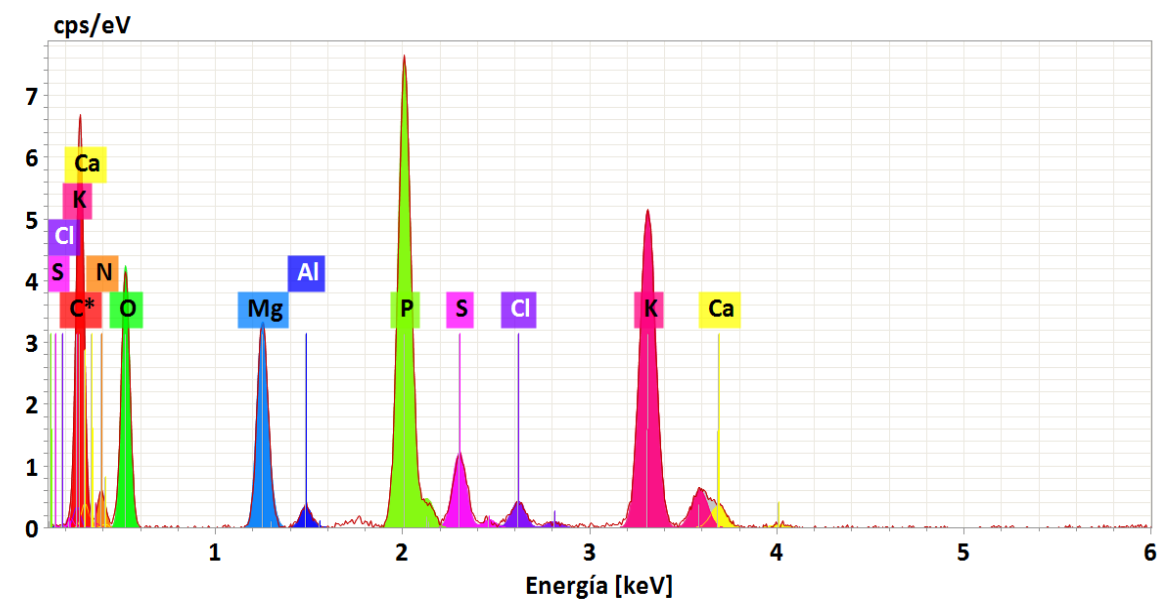


Figura 7: Imagen por Microscopía electrónica de barrido SEM-MO2

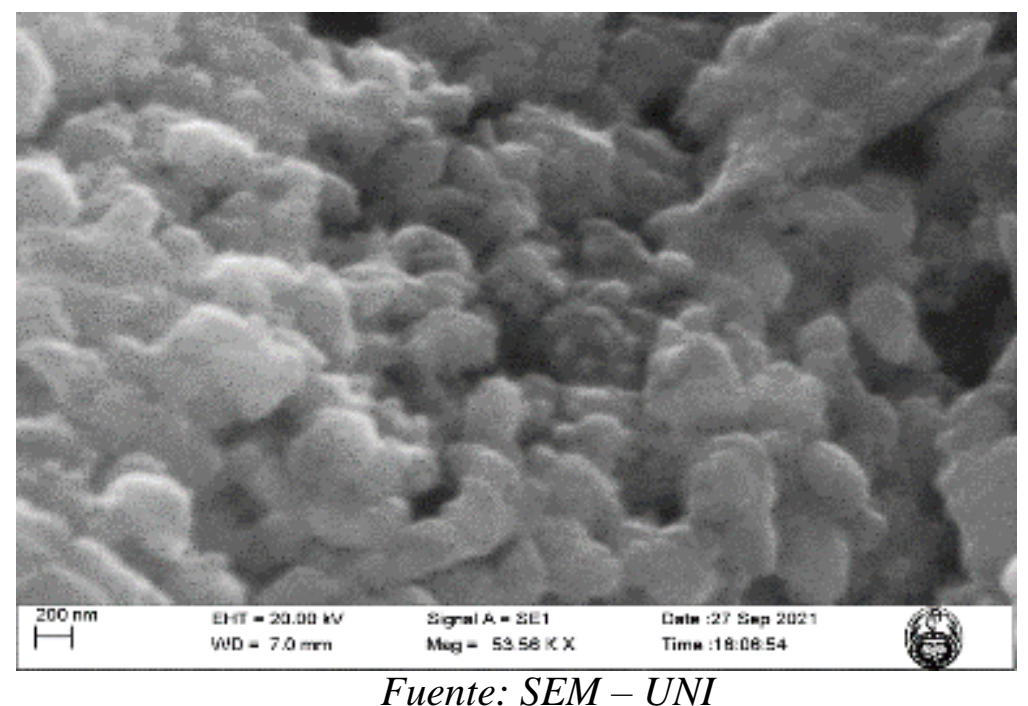

La imagen a escala 200nm, con energía dispersiva de $20.00 \mathrm{KV}$, magnitud 53KX muestra evidencia de polímeros fragmentados por estática adheridos a las excretas, mas no como parte constitutiva de la biomasa.

Habiendo evaluado cada espectro, en la muestra M03 se observó que los elementos descritos como el oxígeno O está presente en un porcentaje atómico del 59.63\% +- un error relativo de $11.58 \%$, el fósforo $\mathrm{P}$ en un $0.72 \%$ del porcentaje atómico, el potasio $\mathrm{K}$ en un $1.22 \%$, el nitrógeno $\mathrm{N}$ en $35.76 \%$, el cloro $\mathrm{Cl}$ en $0.98 \%$ el azufre $\mathrm{S}$ en $0.56 \%$ y el Ca en $0.33 \%$.

Se ha evidenciado un incremento sustancial del nitrógeno, potasio y fósforo, en menor proporción, elementos importantes para considerar una materia fecal con potencial de nutrientes, esto traduce el hecho de que las excretas de los tenebriónidos, convirtieron los polímeros en sustancias químicas que podrían aportar nutrientes al suelo y lograron eliminar los relictos de poliestireno expandido.

Fig. 8: Espectrometría de los elementos químicos de las excretas de Tenebrio molitor, espectro-M03, en base a los picos de energía

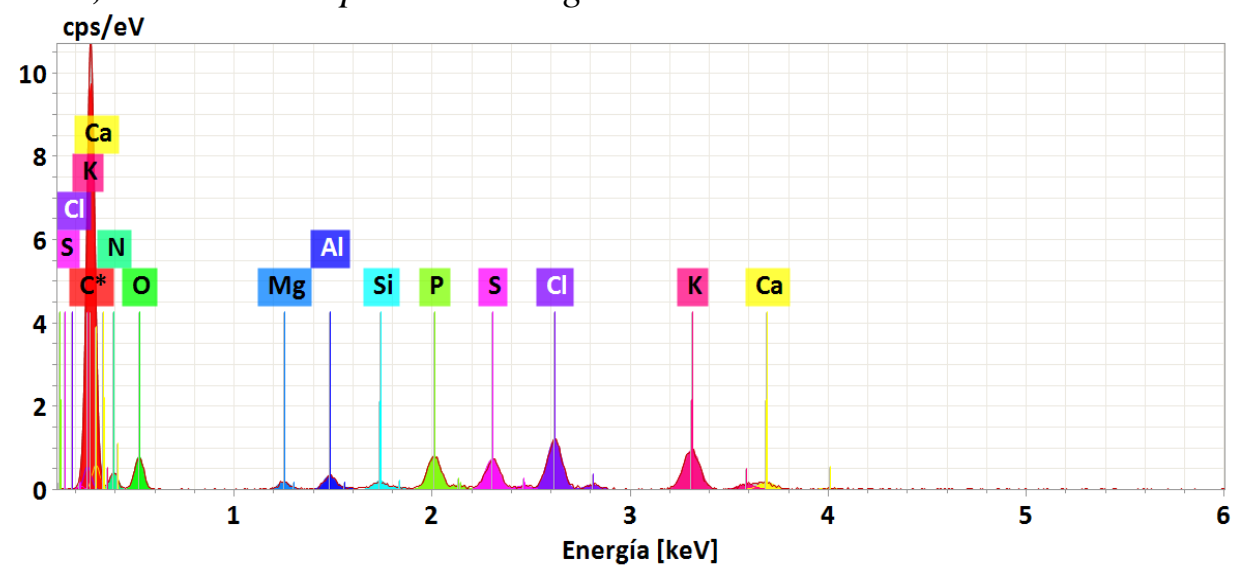


Figura 9: Imagen por Microscopía electrónica de barrido SEM - M03

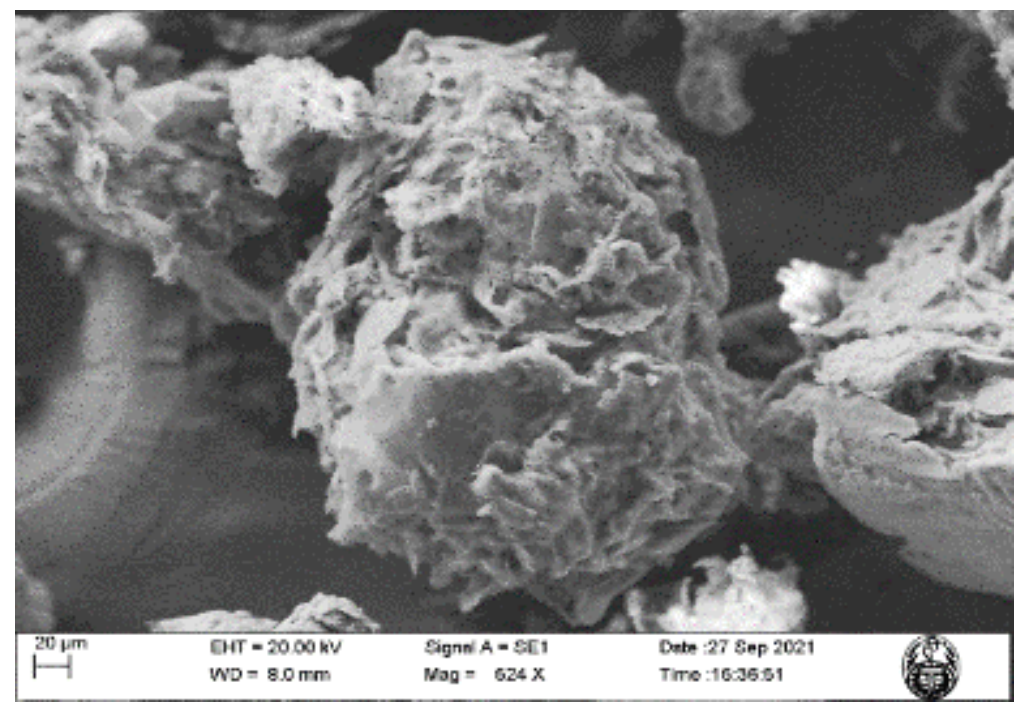

Fuente: SEM - UNI

La imagen a escala 20Um, con energía dispersiva de $20.00 \mathrm{KV}$, magnitud $624 \mathrm{X}$ muestra que no hay evidencia de polímeros fragmentados en las excretas de los tenebrionidos.

La evaluación de cada espectro, en la muestra M04 denotó que los elementos descritos como el oxígeno O está presente en un porcentaje atómico del $27.39 \%$ +- un error relativo de $19.56 \%$, el fósforo $\mathrm{P}$ en un $9.78 \%$ del porcentaje atómico, el potasio $\mathrm{K}$ en un $30.58 \%$, el cloro $\mathrm{Cl}$ en $7.98 \%$ el azufre $\mathrm{S}$ en $8.16 \%$ y el Ca en $4.20 \%$.

Se ha evidenciado un incremento sustancial del fósforo, nitrógeno no se evidencia, el potasio tuvo un incremento muy sustancial con relación a los otros elementos, los tenebriónidos, convirtieron los polímeros en sustancias químicas que podrían aportar nutrientes al suelo y lograron eliminar los relictos de poliestireno expandido.

Figura 10: Espectrometría de los elementos químicos de las excretas de Tenebrio molitor, espectro-M04, en base a los picos de energía

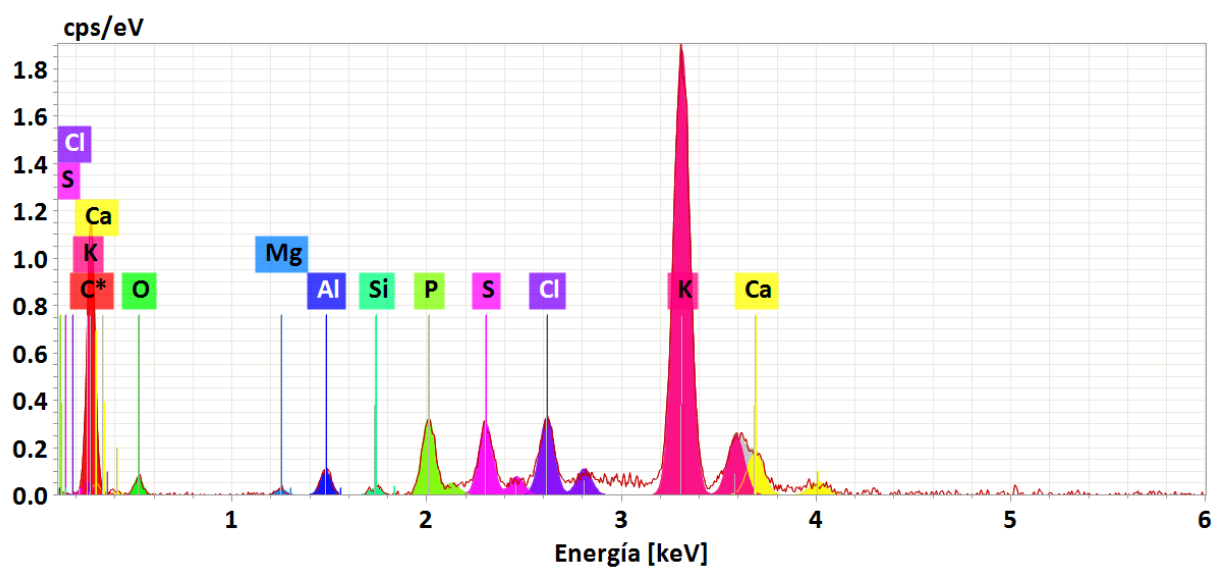


Figura 11: Imagen por Microscopía electrónica de barrido SEM-M04

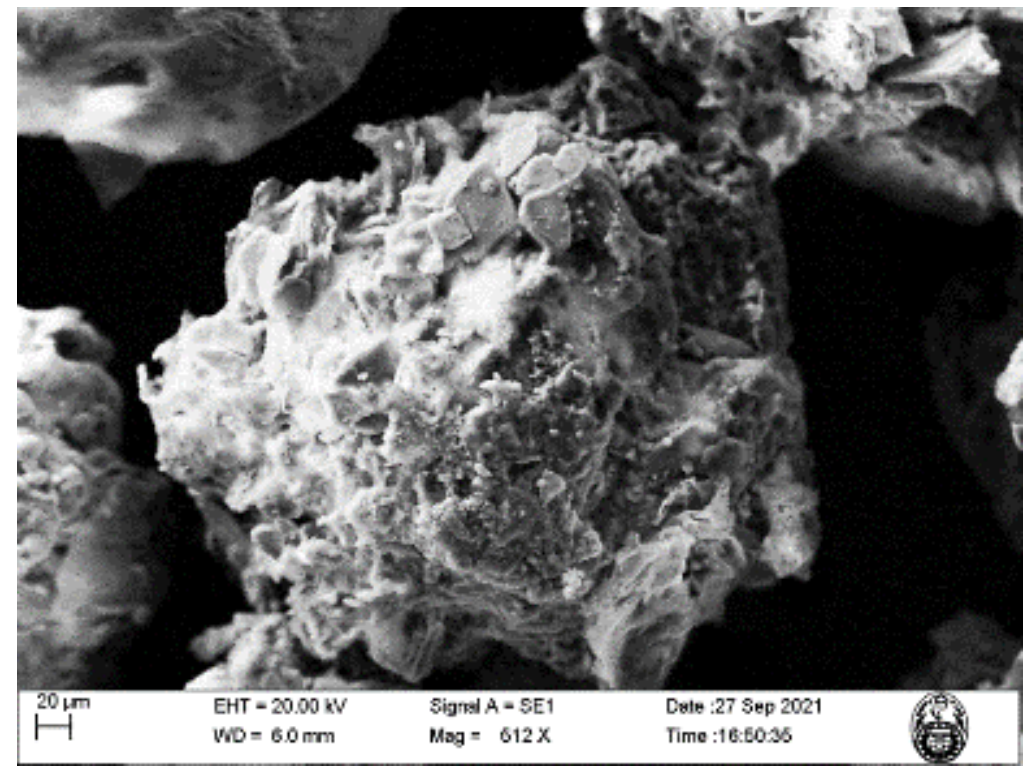

Fuente: SEM - UNI

La imagen a escala $20 \mathrm{Um}$, con energía dispersiva de $20.00 \mathrm{KV}$, magnitud $512 \mathrm{X}$ muestra evidencia de polímeros fragmentados por estática adheridos a las excretas, mas no como parte constitutiva de la biomasa.

Se valoró la composición bioquímica de los desechos generados como parte del proceso de digestión de las larvas de Tenebrio molitor bajo condiciones de laboratorio por espectrometría, evidenciando que los polímeros sintéticos habían sido digeridos por las enterobacterias y generado excretas contenidas en oxígeno, nitrógeno, fósforo y potasio expresado en porcentajes atómicos, dato que representa una evidencia muy relevante, en el contexto de la capacidad de convertir sustancias no biodegradables, en sustancias químicas potencialmente asimilables.

\section{CONSIDERACIONES FINALES}

- Siguiendo los procedimientos pertinentes se logró identificar la especie Enterococcus faecalis ATCC 29212 como una de las enterobacterias capaces de biodegradar el poliestireno expandido, sin embargo, el consorcio bacteriano es más diverso, en ese sentido, es pertinente seguir con investigaciones que identifiquen otras especies degradadoras.

- Al determinar el volumen de poliestireno consumido por los tenebriónidos objeto de estudio a través del balance másico de sus excretas y diferencia gravimétrica inicial y final del polímero de estireno, se pudo evidenciar la actividad biológica de la 
degradación, sin embargo, sólo es en un contexto netamente investigativo y experimental, ya que la idea no es utilizar a la especie Tenebrio molitor como organismo degradador, sino que a través de la biotecnología, se pueda aislar la especie identificada para proliferarla y sea ésta la utilizada para la biodegradación del poliestireno en grandes volúmenes.

- Al valorar la composición bioquímica de las excretas de los tenebriónidos, se pudo evidenciar la transformación bioquímica de los polímeros expandidos en sustancias químicas potencialmente asimilables, lo que significaría un residuo orgánico compostable y con la probabilidad de producir abono.

\section{LISTA DE REFERENCIAS}

Albaracin Liendo, R. L. (2020). Evaluación de las condiciones biológicas y ambientales en Tenebrio molitor que influye en la biodegradación del poliestireno. https://repositorio.upt.edu.pe/bitstream/handle/20.500.12969/1701/AlbarracinLiendo-Renza.pdf? sequence $=1$ \&isAllowed $=y$

Álvarez Estepa, D., \& Botache Laguna, L. (2020). Biodegradación de Plástico con Larvas del Coleóptero Tenebrio molitor como un aporte Interdisciplinar a la Biotecnología

Ambiental.http://repository.pedagogica.edu.co/bitstream/handle/20.500.12209/1 2205

BBC Mundo. (2015). ¿Por qué cada vez más ciudades prohíben el poliestireno? 25- 022018 , Consultado en BBC: http://www.bbc.com/mundo/noticias/2015/07/150701_poliestireno_prohibicion_ lp

Cardozo Sánchez, M. L. (2020). Biodegradación del poliestireno expandido por larvas de Tenebrio molitor l. (Coleóptera: Tenebrionidae), en condiciones de laboratorio.

https://repository.unad.edu.co/bitstream/handle/10596/34873/mlcardozos.pdf?se quence $=1 \&$ is Allowed $=\mathrm{y}$

Daviran Yance, P. A. (2017). Biodegradación de la Espuma de Poliestireno por la larva del Tenebrio molitor para la producción de Abono, 2017. Recuperado el 02 de abril

de 
2021.https://repositorio.ucv.edu.pe/bitstream/handle/20.500.12692/22578/Davira n_YP.pdf?sequence $=1 \&$ isAllowed $=\mathrm{y}$

$\begin{array}{llllll}\text { Environmental Science } \& \quad \text { Technology, } 49 & \text { (20): 12080-12086. DOI: }\end{array}$ 10.1021/acs.est.5b02661

Góngora, J. (2018). El reciclaje en México. de Comercio exterior. http://revistas.bancomext.gob.mx/rce/magazines/757/2/reciclaje_mexico.pdf

Gómez Duque, M., \& Acero, F. (2011). Composición y funciones de la flora bacteriana intestinal. Revista Repertorio De Medicina Y Cirugía,20(2), 74-82. https://doi.org/10.31260/RepertMedCir.v20.n2.2011.680.

Ho, B. (2017). An overview on biodegradation of polystyrene and modified polystyrene: the microbial approach. Critical Reviews in Biotechnology, 38(2), 308-320. $10.1080 / 07388551.2017 .1355293$

López-Cortés, A., Schumannb, P., Pukall, R., Stackebrandtb, E. (2005). Exiguobacterium mexicanum sp. nov. and Exiguobacterium artemiae sp. nov., isolated from the brine shrimp Artemia franciscana. Systematic and Applied Microbiology, 29(3):183-90. DOI: 10.1016/j.syapm.2005.09.007

Otake, Y., Kobayashi, T., Asabe, H., Murakami, N. and Ono, K. (1995), Biodegradation of low-density polyethylene, polystyrene, polyvinyl chloride, and urea formaldehyde resin buried under soil for over 32 years. J. Appl. Polym. Sci., 56: 1789- 1796. DOI:10.1002/app.1995.070561309

Pinto-Tomás. A., L. Uribe-Lorío, Blanco. J., G. Fontecha, Rodríguez. C., M. Mora, Janzen. D., F. Chavarría, Díaz. J., A. Sittenfeld. (2007). Actividades enzimáticas en aislamientos bacterianos de tractos digestivos de larvas y del contenido de pupas de Automeris zugana y Rothschildia lebeau (Lepidoptera: Saturniidae). Revista biología tropical 55 (2): 401-415

Redacción. (2021). Definición de Degradación. Recuperado de: https://conceptodefinicion.de/degradacion/. Consultado el 1 de septiembre del 2021.

Schloss. P., I. Delalibera, Handelsman. J., K. Raffa. (2006). Bacteria Associated with the Guts of Two Wood-Boring Beetles: Anoplophora glabripennis and Saperda vestita (Cerambycidae). Environmental Entomology 35(3): 625-62. 
Terrartropoda. (2013). Ficha gusano de la harina - Tenebrio molitor. Consultado el 20 de noviembre de 2017 en TERRARTROPODA disponible en: https://terrartropoda.wordpress.com/2013/08/11/ficha-gusano-de-la-harinatenebrio molitor/

Vasanthakumar. A., I. Delalibera, Handelsman. J., K. Klepzig, Schloss. P., K. Raffa. (2006) Characterization of Gut-Associated Bacteria in Larvae and Adults of the Southern Pine Beetle, Dendroctonus frontalis Zimmermann. Environmental Entomology 35(6): 1710-1717.

Vasanthakumar. A., J. Handelsman, Schloss. P., 1. Bauer, Raffa. K. (2008) Gut Microbiota of an Invasive Subcortical Beetle, Agrilus planipennis Fairmaire, Across Various Life Stages. Environmental Entomology 37(5): 1344-1353.

Velasco, M. J. (2017). Biodegradación del polietileno de baja densidad, mediante el uso del lepidóptero Gallería mellonella bajo condiciones térmicas controladas. Repositorio UCV. https://hdl.handle.net/20.500.12692/12614

Yang, Y., \& Yang, J. (2015). Biodegradation and Mineralization of Polystyrene by Plastic-Eating Mealworms. Environmental Science \& Technology, 49(20), 12087 - 12093. 10.1021/acs.est.5b02663

Yoshida, S., \& Kosuda, Y. (2016). A bacterium that degrades and assimilates poly ethylene terephthalate.Science, 351(6278), 1196-1199. 10.1126/science.aad (6359) 